\title{
Enhanced Electrochemical Capacitance of Nitrogen-Doped Carbon Nanotubes Synthesized from Amine Flames
}

\author{
Lingmin Liao ${ }^{1}$, Chunxu Pan ${ }^{1,2^{*}}$ \\ ${ }^{1}$ School of Physics and Technology and Key Laboratory of Artificial Micro- and Nano-structures of Ministry of Education, Wuhan \\ University, Wuhan, China; ${ }^{2}$ Center for Electron Microscopy, Wuhan University, Wuhan, China \\ Email: cxpan@whu.edu.cn
}

Received January $10^{\text {th }}, 2011$; revised January $20^{\text {th }}, 2011$; accepted January $25^{\text {th }}, 2011$.

\begin{abstract}
This paper presents a new process for synthesizing a kind of nitrogen- doped carbon nanotubes (N-CNTs) with primarily a 'graphite-like' structure at $N$ substitutions from flames using n-propylamine and n-butylamine as fuels. When the $\mathrm{N}$-CNTs are used as the supercapacitor electrode materials, they exhibit a much larger capacitance than the regular carbon nanotubes (CNTs). It is proposed that the high proportional 'graphite-like' $N$ dopant in the as-grown $N$-CNTs improves their surface chemical activity and conductivity and then results in a desirable performance for electrochemical capacitors.
\end{abstract}

Keywords: Nitrogen-Doped Carbon Nanotubes, Flame Method, Double layer Capacitor, Electrode Materials, Capacitance

\section{Introduction}

Electrochemical capacitor (also called supercapacitor) is an attractive energy storage device due to its high power density, long cycle life, quick charge capability, a wide range of operating temperature, and environment friendly. It has shown a good potential in electric vehicles and electronic devices [1].

As is well known, the electrode material is the key factor determining the performance of the supercapacitor, which is crucially dependent on its conductivity and wettability, besides its intrinsic physical characteristics such as surface area and pore structure. As one form of supercapacitors, electrochemical double layer capacitor (EDLC) is based on the separation of electronic and ionic charges at the electrode-electrolyte interface. Generally, carbon materials are frequently used as the electrode materials in EDLCs. In the recent years, carbon nanotubes (CNTs) have been widely studied as the promising electrode materials, due to their high conductivity, large specific surface area, narrow distribution of pore sizes and chemical stability [2].

However, when the CNTs synthesized from a conventional chemical vapor deposition (CVD) process are used as the electrode materials, the capacitance is restrained by their low surface wettability owing to few defective sites in the sidewalls. Previously, most of the researches focus on using complicated activation post treatments for CNTs to improve their electrochemical capacitance, such as acid treatment [3], surface chemical modification [4], heat treatment [5], and so on. However, these post treatments are always complex and complicated in processes. Recent research has shown that surfacial nitrogen $(\mathrm{N})$ functionality for the regular carbon materials, such as mesoporous carbon and carbon gels, is an efficient method for increasing the capacitance and stability due to the pseudofaradaic effect and surface chemical property $[6,7]$. During the past few years, some remarkable progress has been made in nitrogen incorporation into CNTs. For example, nitrogen-doped carbon nanotubes (N-CNTs) have been synthesized from the CVD process $[8,9]$. And it has been recognized that the $\mathrm{N}$ dopant in N-CNTs mainly has two forms, that is, 'pyridine-like' (one $\mathrm{N}$ atom bonded to two $\mathrm{C}$ atoms) and 'graphite-like' (one $\mathrm{N}$ atom bonded to three $\mathrm{C}$ atoms as if substituted in a graphitic network) bonding configurations [8-10]. Generally, for the most commonly used CVD process, the 'pyridine- like' N-CNTs are mainly yielded. As the 
structure of material determines its properties, these different $\mathrm{N}$ doping structures would induce different effects on the performance of CNTs [11].

As a kind of $\mathrm{N}$ functionalized carbon nanomaterials, the N-CNTs are expected to be used as EDLC electrode materials with desired capacitance. However, as we know, related research works mainly deal with the dominantly 'pyridine-like' N-CNTs from the CVD process currently [12-14]. In the present work, the N-CNTs with primarily a 'graphite-like' structure at $\mathrm{N}$ substitutions were firstly achieved from amine flames. When they were applied as the electrode materials for EDLCs, a greater electrochemical capacitance was obtained which showed the more promising applicability to supercapacitors.

\section{Experimental}

The N-CNTs were simply synthesized utilizing a common laboratorial alcohol burner. Two kinds of $\mathrm{N}$-contained liquid amines, n-propylamine and $n$-butylamine, were selected as the fuels. The substrate was a pure copper plate sized $15 \times 15 \mathrm{~mm}$, which was pretreated by the following process: firstly, the sampling surface of the substrate was mechanically polished to a mirror finish as for preparation of metallographic samples; secondly, a thin nanocrystalline Ni layer was pulse plated upon the surface as the catalyst. The detailed plating process has been described elsewhere [15]. Finally, the plated substrates were inserted into the flames for a certain time and a layer of black materials were produced on the sampling surface of the substrates.

Then the flame-synthesized materials were purified according to the following process: 1) Dispersing the carbon materials in deionized water and ultrasonically treated for one hour at room temperature; 2) Keeping the suspension still for ten hours and drying at $100^{\circ} \mathrm{C}$ for five hours; 3) Putting the dried products into a $6 \mathrm{M}$ $\mathrm{HCl}$ solution and stirred for twenty hours constantly, and then keeping the solution still until a clarified supernatant was obtained; 4) Pouring off the supernatant, and re-dispersing the carbon materials in deionized water and stirring for thirty minutes, and then keeping still until the suspension was stratified; 5) Repeating the fourth step for several times until a neutral $\mathrm{pH}$ suspension was obtained; 6 ) The final products were dried at $100^{\circ} \mathrm{C}$ for four hours.

The morphologies and microstructuries of the N-CNTs were characterized using a field-emission gun scanning electron microscope (FEG-SEM, FEI SIRION, The Netherlands) and high-resolution transmission electron microscope (HRTEM, JEOL JEM 2010FEF, Japan). The Fourier transform infrared (FTIR) spectrum was recorded using $\mathrm{KBr}$ wafers in conjunction with a Thermo Nicolet Avatar 370 infrared spectrometer. The elemental compo- sitions of the N-CNTs were quantified using a X-ray photoelectron spectroscope (XPS) (VG, Multilab 2000). And XPS measurements were performed by using a monochromatic AlK X-ray radiation at a pass energy of $25 \mathrm{eV}$. The laser Raman spectrum was performed in an England Renishaw-1000 laser Raman spectroscopy instrument in the back-scattering configuration at room temperature, using $514.5 \mathrm{~nm}$ line from an $\mathrm{Ar}$ ion laser. Nitrogen adsorption isotherms were measured with a static volumetric method specific surface area and pore size distribution analyzer (JW-BK, Beijing JWGB Sci. \& Tech. Co., Ltd) at liquid nitrogen temperature.

For comparison, four kinds of CNTs, that is, N-CNTs from $n$-butylamine flame (labeled as N-CNTs(B)), NCNTs from n-propylamine flame (N-CNTs(P)), CNTs from ethanol flame (E-CNTs, produced as described in [15]) and CNTs derived from CVD (C-CNTs, supplied by Shenzhen Nanotechnologies Co. Ltd., China, with a diameter of 40-60 nm), were electrochemically characterized by a CHI $660 \mathrm{C}$ electrochemical workstation. The cyclic voltammograms (CV) and galvanostatic chargedischarge (GCD) tests were carried out using a typical three-electrode cell in $6 \mathrm{M} \mathrm{KOH}$ solution.

The preparation of the working electrode was as follows: the CNTs $(20 \mathrm{mg})$ were firstly mixed and ground with $10 \mathrm{wt} \%$ Polytetrafluoroethene (PTFE) as a binder; then they were pressed on a nickel foam current electrode sized $1 \times 1 \mathrm{~cm}$ to $0.7 \mathrm{~mm}$ in thickness. A platinum wire and a saturated calomel electrode (SCE) were used as counter and reference electrodes, respectively.

\section{Results and Discussions}

Figure 1 shows the SEM morphologies of the combustion products from $n$-propylamine and $n$-butylamine flame. It could be observed that they are all orderly grown fibrillose structure with diameters in a range of 40-60 $\mathrm{nm}$ and lengths in several micrometers.

In order to demonstrate the formation of N-CNTs from amine flames, FTIR spectroscopy and XPS were used to clarify the $\mathrm{N}$ doping configuration. Figure 2 illustrates the FTIR spectra of different CNTs, and the peak locations and corresponding groups are listed in Table 1. Clearly, there are carboxyl groups $(-\mathrm{COOH})$ and alcohol groups $\left(-\mathrm{CH}_{2} \mathrm{OH}\right)$ existing on the E-CNT surface [16]. However, for the CNTs from the amine flames, several different peaks confirm the stretching vibration of $\mathrm{C}-\mathrm{N}$, $\mathrm{C}=\mathrm{N}$ and $\mathrm{C} \equiv \mathrm{N}$. Therefore, the combustion products from amine flames mainly contain $\mathrm{C}-\mathrm{N}, \mathrm{C}=\mathrm{N}$ and $\mathrm{C} \equiv \mathrm{N}$ bonds, which demonstrates the formation of $\mathrm{N}$ doped structure, that is, the N-CNTs. Additionally, comparing the absorption intensities of the peaks in the range of 2000-2300 $\mathrm{cm}^{-1}$ (Figure 2(b)), it is found that N-CNTs(B) possess more $\mathrm{C} \equiv \mathrm{N}$ bonds than $\mathrm{N}-\mathrm{CNTs}(\mathrm{P})$. 


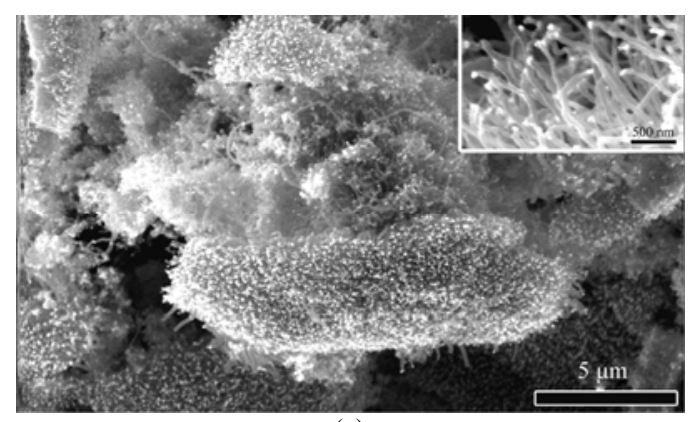

(a)

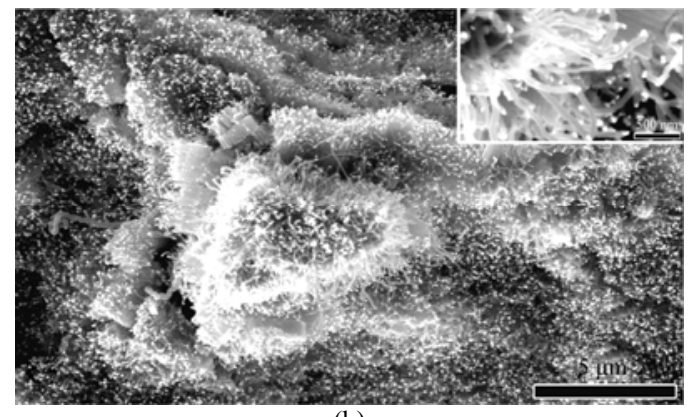

(b)

Figure 1. SEM morphologies of combustion products grown on the substrate in different amine flames: (a) n-propylamine; (b) $n$-butylamine.

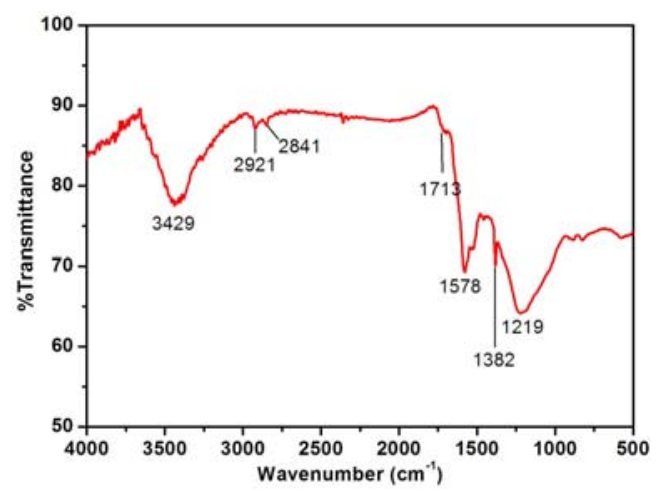

(a)

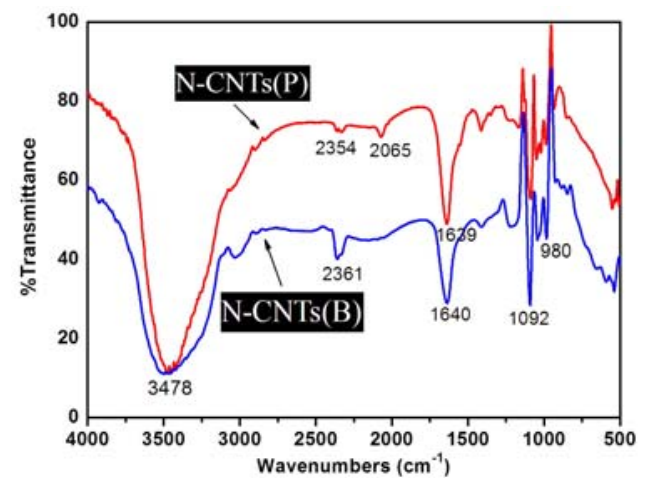

(b)

Figure 2. (a) FTIR spectrum of E-CNTs; (b) FTIR spectra of CNTs from the two amine flames.
Table 1. Assignment of FTIR spectra of E-CNTs, N-CNTs(P) and N-CNTs(B).

\begin{tabular}{ccl}
\hline Material & $\begin{array}{c}\text { Absorption } \\
\text { wavenumber } \\
\left(\mathrm{cm}^{-1}\right)\end{array}$ & \multicolumn{1}{c}{ Functional group } \\
\hline & 3429 & O-H stretching \\
2921,2841 & C-H stretching \\
E-CNTs & 1713 & C=O stretching \\
& 1578 & -COO asymmetrical stretching \\
& 1382 & C-H in-plane bending \\
& 1219 & C-O stretching \\
& 3478 & O-H stretching \\
N-CNTs(P) & $2000-2400$ & C $\equiv$ N stretching \\
N-CNTs(B) & 1639 & $\mathrm{C}=\mathrm{N}$ stretching \\
& $900-1100$ & N heterocyclic ring modes \\
\hline
\end{tabular}

Figure 3 gives the $\mathrm{C}$ 1s and $\mathrm{N}$ 1s XPS spectra of the $\mathrm{N}-\mathrm{CNTs}$ from the amine flames. The results reveal that the concentration of $\mathrm{N}$ in $\mathrm{N}-\mathrm{CNTs}(\mathrm{P})$ is about 3 at $\%$, which is estimated from the area ratio of the $\mathrm{N} 1 \mathrm{~s}$ and $\mathrm{C}$ $1 \mathrm{~s}$ peaks. And the N-CNTs(B) contain a smaller quantity of $\mathrm{N}$ (2.5 at\%), which is more likely attributed to the lower $\mathrm{N}$ content in the $n$-butylamine fuel. The asymmetric shapes of the $\mathrm{N}$ 1s peaks suggest the existence of at least two main components and could be deconvoluted into two peaks A and B at 401 and $399 \mathrm{eV}$ with Gaussian and Lorentzian mixed function, as shown in Figures 3(b) and 3(d).

In general, the electronic structures of $\mathrm{N}$ atoms have diverse forms, i.e., 'graphite-like' structure, 'pyridinelike' structure, cross-linked $\mathrm{sp}^{3}$ structure, nitrile structure $\left(\mathrm{C} \equiv \mathrm{N}\right.$ groups) and intercalated $\mathrm{N}_{2}$ molecules [9,17-19]. The 'pyridine-like' and 'graphite-like' bonding configurations belong to the $\mathrm{N}$ doping structures in CNTs. According to Figure 3 and the FTIR results in Figure 2(b), the present N-CNTs consist of the 'graphite-like' bonding configurations corresponding to the peak $\mathrm{A}$, and $\mathrm{C} \equiv \mathrm{N}$ bonding configurations related to the peak $\mathrm{B}$, following the peak assignment of $\mathrm{N} 1 \mathrm{~s}$ for $\mathrm{N}-\mathrm{CNT}$ s and the $\mathrm{CNx}$ films $[8,9,18,20]$, which has been detailedly explained in our recent work [21]. The area ratio of the peak $\mathrm{A} / \mathrm{B}$ is $7: 3$ and $1: 1$ for the N-CNTs from $n$-propylamine flame and $n$-butylamine flame, respectively. It confirms that the $\mathrm{N}$ 1s spectra almost show mainly the band at $401 \mathrm{eV}$, which means the present N-CNTs from amine flames are primarily with a 'graphite-like' structure at N substitutions due to the special formation condition of high temperature and oxidative environment in amine flames [21].

Compared with HRTEM images of C-CNTs (Figure 4(a)) and E-CNTs (Figure 4(b)), the N-CNTs from amine flames are hollow-centered bamboo-like, as shown in Figure 4(c), which is induced by the incorporation of 


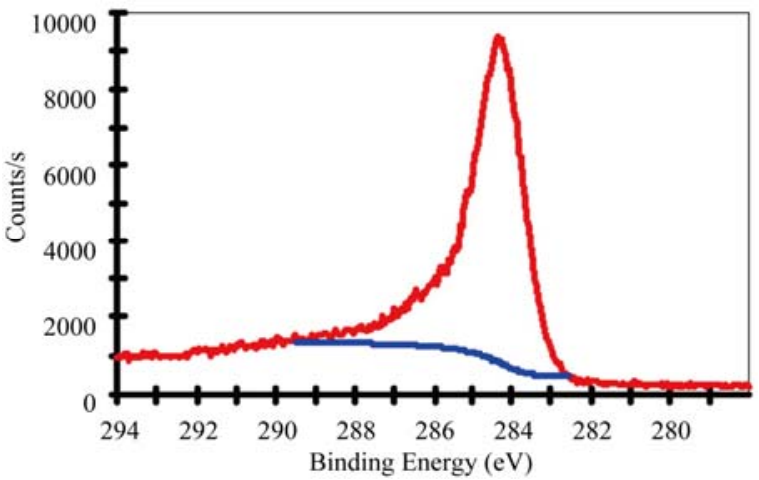

(a)

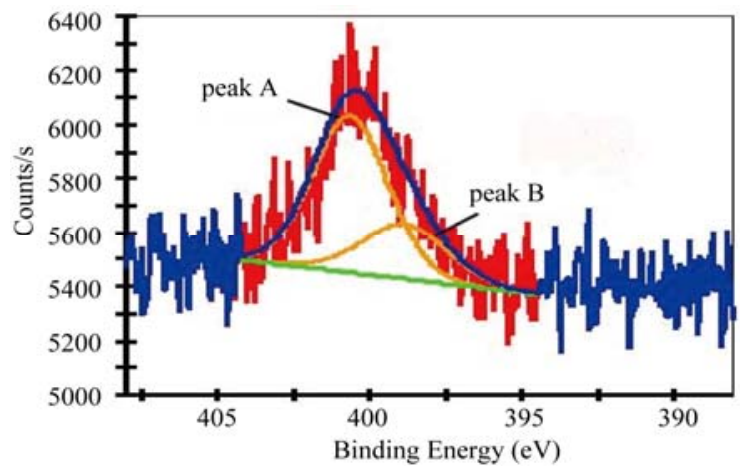

(b)

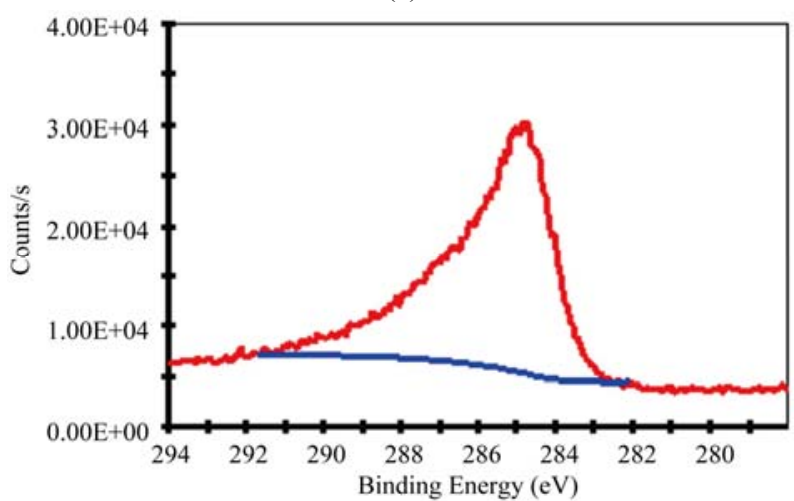

(c)

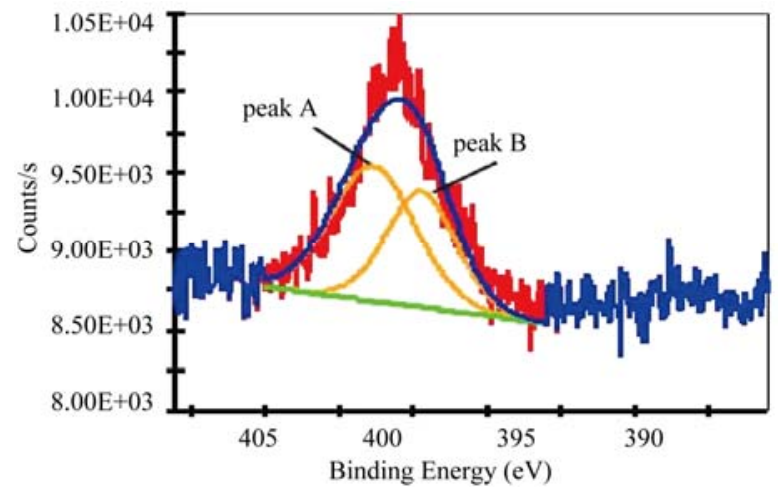

(d)

Figure 3. (a) C 1s XPS spectra and (b) N 1s XPS spectra of $\mathrm{N}$-CNTs synthesized in (a) $n$-propylamine flame; (c) C $1 \mathrm{~s}$ XPS spectra and (d) N 1s XPS spectra of N-CNTs synthesized in $n$-butylamine flame.

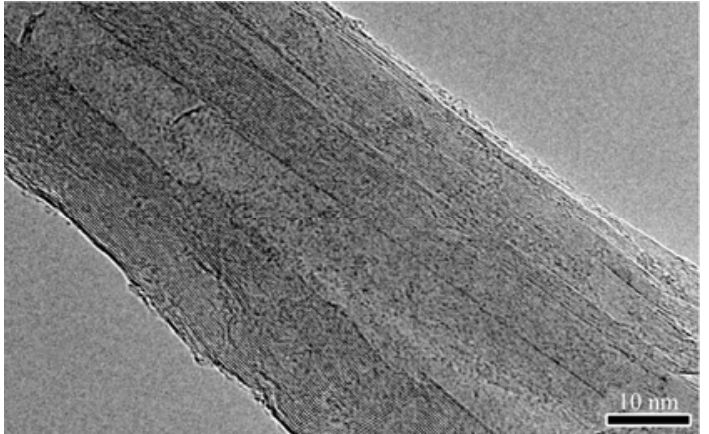

(a)

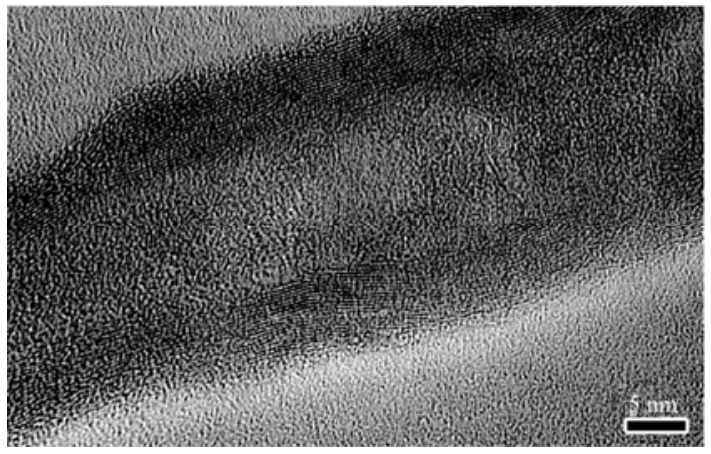

(b)

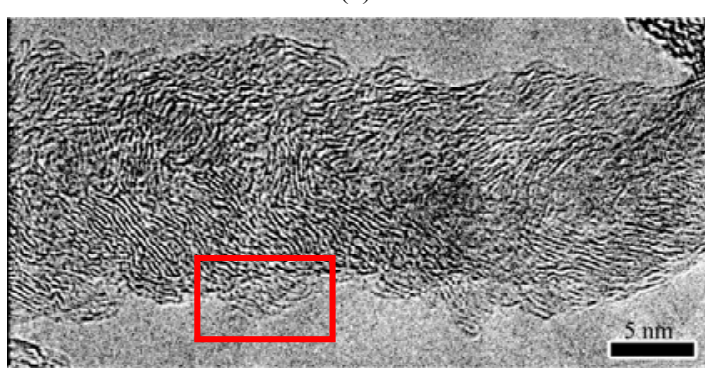

(c)

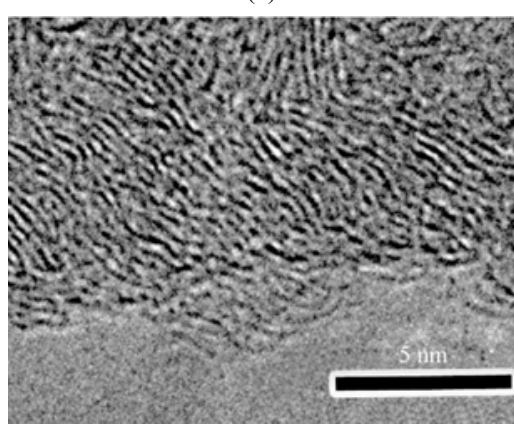

(d)

Figure 4. Typical HRTEM images of (a) C-CNTs, (b) ECNTs and (c) N-CNTs synthesized in amine flames; (d) A magnified view of the squared area in (c).

$\mathrm{N}$ atoms in graphite layers [22]. And the rugosity of the outer wall (Figure 4(d)) further confirms that the tubes have superficial defects via $\mathrm{N}$ wall doping.

Figure 5 shows Raman spectra of the N-CNTs from amine flames. The intensity ratios $I_{\mathrm{D}} / I_{\mathrm{G}}$ of all N-CNTs 
are less than 1, which also confirms the presence of CNT structure. In addition, the $I_{\mathrm{D}} / I_{\mathrm{G}}$ ratio of the N-CNTs from $n$-butylamine flame is 0.7 , which is smaller than those from $n$-propylamine flame (0.8). It suggests that there are fewer defective sites on the surface of the former $\mathrm{N}$ CNTs than the latter, which is resulted from a smaller quantity of $\mathrm{N}$ atoms doped in graphite structures of the N-CNTs from $n$-butylamine flame, and consistent with the XPS results.

Nitrogen sorption isotherms of different CNTs (Figure (6)) show the uptake in hysteresis loops for E-CNTs, $\mathrm{N}-\mathrm{CNTs}(\mathrm{B})$ and $\mathrm{N}-\mathrm{CNTs}(\mathrm{P})$ all appear at lower pressure (near $\left.0.5 \mathrm{P} / \mathrm{P}_{0}\right)$ than $\mathrm{C}-\mathrm{CNTs}\left(0.8 \mathrm{P} / \mathrm{P}_{0}\right)$, which reveals that the three kinds of CNTs have more micropore structures than C-CNTs. The surface area and pore volume are $106 \mathrm{~m}^{2} / \mathrm{g}$ and $0.63 \mathrm{~cm}^{3} / \mathrm{g}$ for C-CNTs, $254 \mathrm{~m}^{2} / \mathrm{g}$ and 0.38 $\mathrm{cm}^{3} / \mathrm{g}$ for E-CNTs, $225 \mathrm{~m}^{2} / \mathrm{g}$ and $0.37 \mathrm{~cm}^{3} / \mathrm{g}$ for $\mathrm{N}$ CNTs(B), $219 \mathrm{~m}^{2} / \mathrm{g}$ and $0.36 \mathrm{~cm}^{3} / \mathrm{g}$ for N-CNTs(P), respectively. The results suggest that for $\mathrm{N}-\mathrm{CNTs}(\mathrm{B}), \mathrm{N}-$ CNTs $(\mathrm{P})$ and E-CNTs, the surface area and the proportion of micropores of nanotubes have been improved but not much compared with C-CNTs. And it is found that the two kinds of N-CNTs have similar surface area and pore structures with E-CNTs.

Figure 7(a) illustrates the $\mathrm{CV}$ curves of electrodes fabricated with N-CNTs(B), N-CNTs(P), E-CNTs and CCNTs at a scan rate of $20 \mathrm{mVs}^{-1}$. It is found that the specific capacitance $(\mathrm{Cg})$ of the $\mathrm{C}$-CNTs is much smaller than that of the other electrodes. And the $\mathrm{Cg}$ of the E-CNTs, N-CNTs(B) and N-CNTs(P) are $28 \mathrm{~F} / \mathrm{g}, 31 \mathrm{~F} / \mathrm{g}$ and $37 \mathrm{~F} / \mathrm{g}$, respectively, as shown in Figure 7(c). Figure 7(b) gives the galvanostatic charge-discharge (GCD) curves for different CNT electrodes at a current density of $0.25 \mathrm{~A} / \mathrm{g}$. The $\mathrm{Cg}$ of C-CNTs, E-CNTs, N-CNTs(B) and $\mathrm{N}-\mathrm{CNTs}(\mathrm{P})$ are respectively evaluated to be $3 \mathrm{~F} / \mathrm{g}, 37$ $\mathrm{F} / \mathrm{g}, 41 \mathrm{~F} / \mathrm{g}$ and $48 \mathrm{~F} / \mathrm{g}$, which shows the similar increment tendency with the result of $\mathrm{CV}$ tests, as shown in

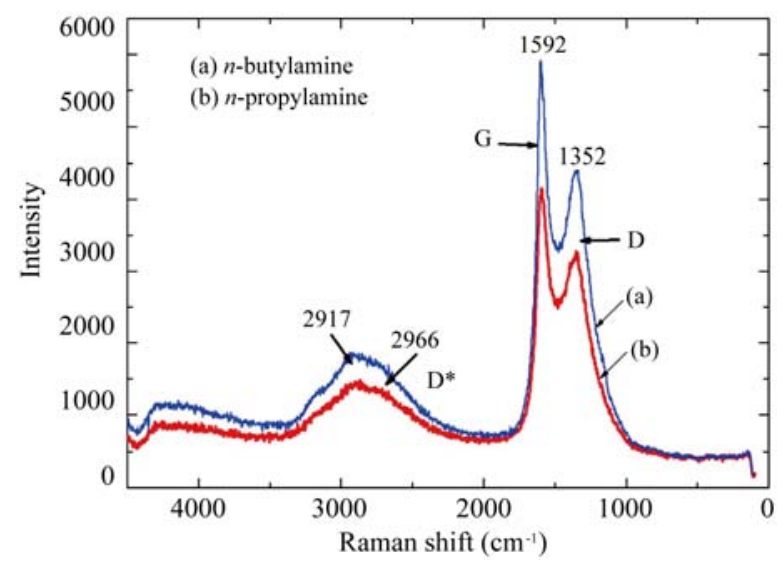

Figure 5. Raman spectra of N-CNTs synthesized in different amine flames: (a) $n$-butylamine; (b) $n$-propylamine.

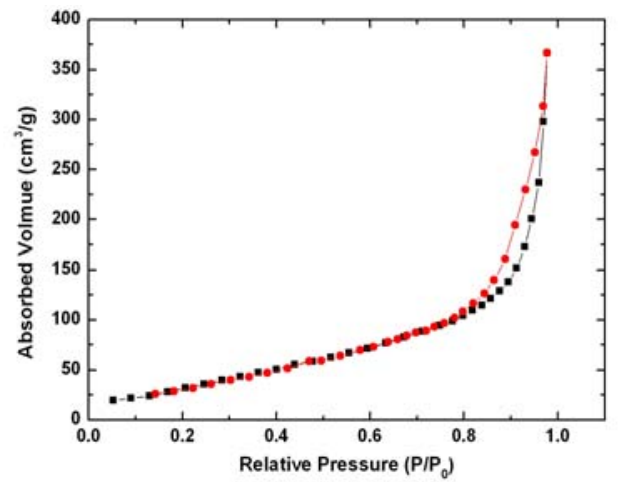

(a)

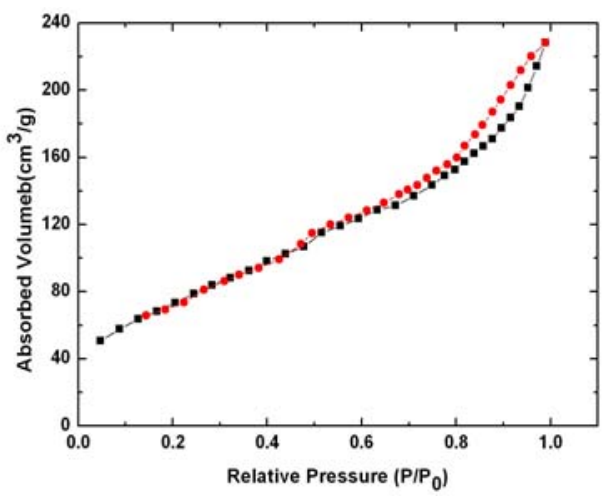

(b)

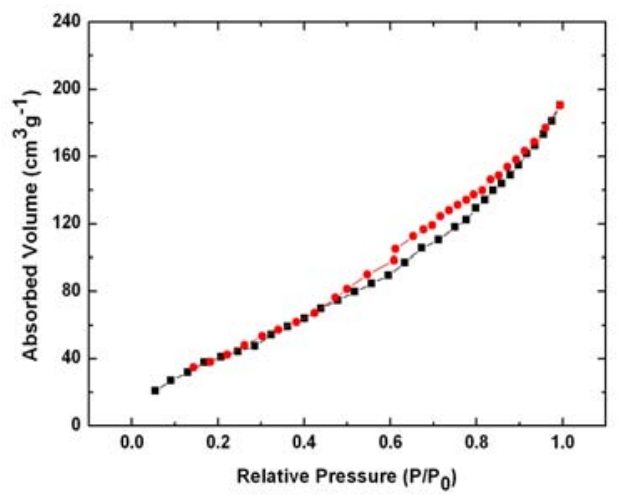

(c)

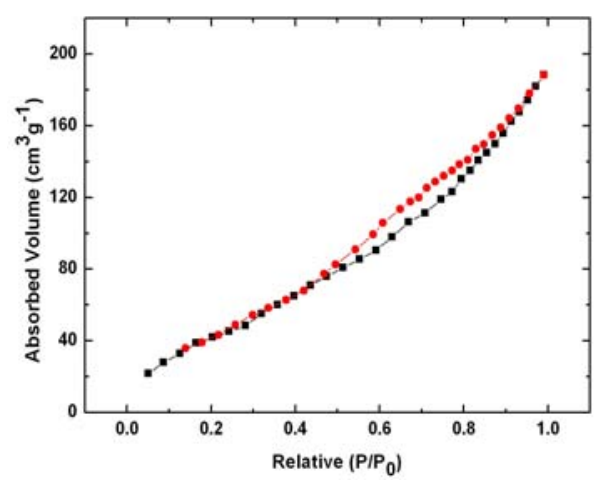

(d)

Figure 6. Nitrogen sorption isotherms of different CNTs: (a) C-CNTs; (b) F-CNTs; (c) N-CNTs(B); (d) N-CNTs(P). 


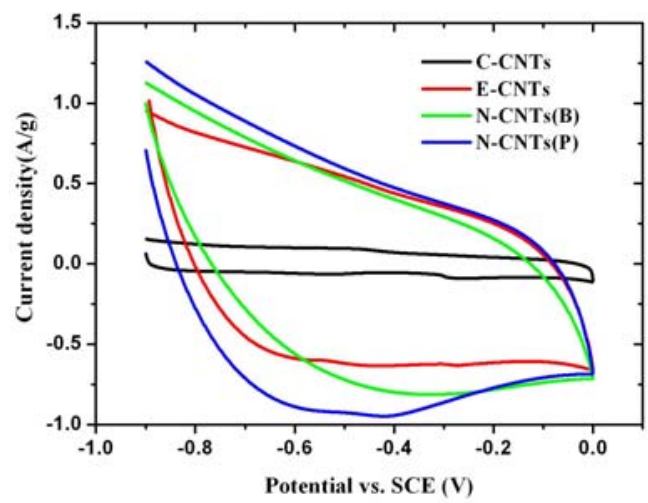

(a)

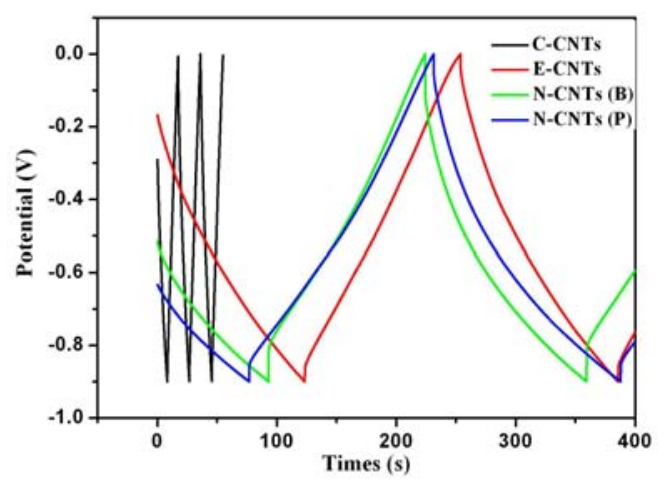

(b)

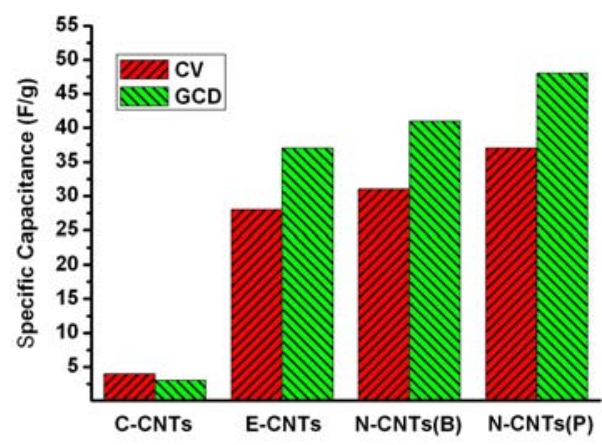

(c)

Figure 7. (a) CV curves for different CNT electrodes at a scan rate of $20 \mathrm{mV} \mathrm{s}^{-1}$; (b) GCD curves for different CNT electrodes at a current density of $0.25 \mathrm{~A} / \mathrm{g}$; (c) Bar graphs of the $\mathrm{Cg}$ of different CNT electrodes evaluated from the $\mathrm{CV}$ $\left(20 \mathrm{mV} \mathrm{s}^{-1}\right)$ and GCD (0.25 A/g) tests.

Figure 7(c), that is, N-CNTs $(\mathrm{P})>\mathrm{N}-\mathrm{CNTs}(\mathrm{B})>\mathrm{F}-\mathrm{CNTs}$ $\gg$ C-CNTs. As shown above, N-CNTs(B), N-CNTs(P) and E-CNTs all possess just a little larger surface area and proportion of micropores than C-CNTs. However, the $\mathrm{Cg}$ of the three kinds of CNTs, especially for $\mathrm{N}$ CNTs(P), is over 10 times than that of C-CNTs. Apparently, this remarkable improvement of electrochemical capacitance for these CNTs derived from flames should be closely related to their wettability and conductivity.
Generally, regular C-CNTs are of an intact tubular structure with few defects in the sidewall and chemically inert, which results in their weak wettability and small electrochemical capacitance. However, E-CNTs with functional groups $\left(-\mathrm{COOH}\right.$ and $\left.-\mathrm{CH}_{2} \mathrm{OH}\right)$ on the surface and the N-CNTs with superficial defective sites due to $\mathrm{N}$ incorporation can effectively release the chemical inertness of CNTs and help to the aqueous $\mathrm{KOH}$ electrolyte wetting and the formation of electric double layer at the electrode/electrolyte interface [16,22]. Consequently, the $\mathrm{N}-\mathrm{CNT}$ from amine flames and E-CNTs exhibit much larger capacitance than the regular C-CNTs.

Furthermore, compared with E-CNTs, the two kinds of N-CNTs actually have smaller surface area and similar pore structure, which is also described above. Here, the $\mathrm{N}-\mathrm{CNTs}$ from amine flames, especially for $\mathrm{N}-\mathrm{CNTs}(\mathrm{P})$, represent a greater electrochemical capacitance than E-CNTs, which is attributed to their unique high proportional 'graphite-like' $\mathrm{N}$ doping configuration in the walls. The interpretation is as follows.

As is well known, multi-walled nanotube are mostly considered to be metallic. Then, for the CNTs functionalized by $-\mathrm{COOH}$ and $-\mathrm{CH}_{2} \mathrm{OH}$, the hybridization between the $\mathrm{sp}^{3}$ functional groups and the nanotubes opens up a new band gap and introduces an impurity state in the middle of the gap region [16,23]. The impurity state will act as a strong scattering center for the conduction carriers around the Fermi level and increase the inherent resistance of CNTs. And according to the theoretical calculation by Zhao et al. [23], any modification of the $\mathrm{C}-\mathrm{C}$ bonding structure away from the $\mathrm{sp}^{2}$ bonding configuration will induce an impurity state in the gap region. Therefore, both $\mathrm{C} \equiv \mathrm{N}$ and 'pyridine-like' $\mathrm{N}$ doping configuration in the CNT structure have similar influence upon its energy band structure and conductivity with $-\mathrm{COOH}$ and $-\mathrm{CH}_{2} \mathrm{OH}$ functionalization.

On the other hand, the substitutional 'graphite-like' $\mathrm{N}$ doping does not disturb the $\mathrm{sp}^{2}$ hybridization of the surrounding $\mathrm{C}$ atoms to form an additional impurity state. And the extra valence electrons from the $\mathrm{N}$ dopant occupy the CNT conduction band and shift the Fermi level toward the conduction band [23,24], which will improve the conductivity of CNTs. Therefore, with many 'graphite-like' $\mathrm{N}$ structures in the tube walls, the N-CNTs from amine flames possess better electronic properties and subsequently larger electrochemical capacitance than the E-CNTs. In addition, because of N-CNTs(P) containing larger quantity of $\mathrm{N}$ dopant and higher proportion of 'graphite-like' $\mathrm{N}$ structures than $\mathrm{N}-\mathrm{CNTs}(\mathrm{B})$, the former provides more superior surface chemical activity and conductivity, which results in its higher electrochemical capacitance.

\section{Conclusions}

In summary, the N-CNTs with primarily 'graphite-like' $\mathrm{N}$ substitution structures can be simply synthesized from 
amine flames. When used as the EDLC electrode materials, they show a greater capacitance than the regular CNTs, which is attributed to the improved surface chemical activity and conductivity of CNTs induced by the high proportion of 'graphite-like' $\mathrm{N}$ dopant in the tube walls. It is expected that the N-CNTs are much promising for the potential application in supercapacitors.

\section{Acknowledgements}

This work was supported by the Specialized Research Fund for the Doctoral Program of Higher Education (No. 20070486016.), Ministry of Education, China, the National Basic Research Program of China (973 Program) (No. 2009CB939705), and the National Nature Science Foundation of China (No. J0830310).

\section{REFERENCES}

[1] A. Burke, "Ultracapacitors: Why, How, and Where is the Technology," Journal of Power Sources, Vol. 91, No. 1, 2000, pp. 37-50. doi:10.1016/S0378-7753(00)00485-7

[2] E. Frackowiak, K. Metenier, V. Bertagna and F. Beguin, "Supercapacitor Electrodes from Multiwalled Carbon Nanotubes," Applied Physics Letters, Vol. 77, No. 15, 2000, pp. 2421-2423. doi:10.1063/1.1290146

[3] H. J. Kim, K. K. Jeon, K. H. An, C. Kim, J. G. Heo, S. C. Lim, D. J. Bae and Y. H. Lee, "Exfoliation of SingleWalled Carbon Nanotubes by Electrochemical Treatment in a Nitric Acid," Advanced Materials, Vol. 15, No. 20, 2003, pp. 1757-1760. doi:10.1002/adma.200304942

[4] K. H. An, W. S. Kim, Y. S. Park, Y. C. Choi, S. M. Lee, D. C. Chung, D. J. Bae, S. C. Lim and Y. H. Lee, "Supercapacitors Using Single-Walled Carbon Nanotube Electrodes," Advanced Materials, Vol. 13, No. 7, 2001, pp. 497-500.

doi:10.1002/1521-4095(200104)13:7<497::AID-ADMA4 97>3.0.CO;2-H

[5] E. Raymundo-Piñero, D. Cazorla-Amorós, A. LinaresSolano, S. Delpeux, E. Frackowiak, K. Szostak and F. Beguin, "High Surface Area Carbon Nanotubes Prepared by Chemical Activation," Carbon, Vol. 40, No. 9, 2002, pp. 1614-1617. doi:10.1016/S0008-6223(02)00134-3

[6] W. Li, D. Chen, Z. Li, Y. Shi, Y. Wan, G. Wang, Z. Jiang and D. Zhao, "Nitrogen-Containing Carbon Spheres with very Large Uniform Mesopores: The Superior Electrode Materials for EDLC in Organic Electrolyte," Carbon, Vol. 45, No. 9, 2007, pp. 1757-1763. doi:10.1016/j.carbon.2007.05.004

[7] K. Y. Kang, S. J. Hong, B. I. Lee and J. S. Lee, "Enhanced Electrochemical Capacitance of Nitrogen-Doped Carbon Gels Synthesized by Microwave-Assisted Polymerization of Resorcinol and Formaldehyde," Electro- chemistry Communications, Vol. 10, No. 7, 2008, pp. 1105-1108.

doi:10.1016/j.elecom.2008.05.029

[8] M. Terrones, P. M. Ajayan, F. Banhart, X. Blase, D. L. Carroll, J. C. Charlier, R. Czerw, B. Foley, N. Grobert, R. Kamalakaran, P. Kohler-Redlich, M. Rühle, T. Seeger and H. Terrones, "N-Doping and Coalescence of Carbon Nanotubes: Synthesis and Electronic Properties," Applied Physics A, Vol. 74, No. 3, 2002, pp. 355-361. doi: $10.1007 / \mathrm{s} 003390201278$

[9] R. Czerw, M. Terrones, J. C. Charlier, X. Blasé, B. Foley, R. Kamalakaran, N. Grobert, H. Terrones, D. Tekleab, P. M. Ajayan, W. Blau, M. Rühle, D. L. Carroll, "Identification of Electron Donor States in N-Doped Carbon Nanotubes," Nano Letters, Vol. 1, No. 9, 2001, pp. 457-460. doi: $10.1021 / \mathrm{n} 1015549 \mathrm{q}$

[10] J. W. Jang, C. E. Lee, S. C. Lyu, T. J. Lee and C. J. Lee, "Structural Study of Nitrogen-Doping Effects in Bambooshaped Multiwalled Carbon Nanotubes," Applied physics letters, Vol. 84, No. 15, 2004, pp. 2877-2879. doi:10.1063/1.1697624

[11] M. Zhao, Y. Xia, J. P. Lewis and R. Zhang, "First-Principles Calculations for Nitrogen-Containing Single-Walled Carbon Nanotubes," Journal of Applied Physics, Vol. 94, No. 4, 2003, pp. 2398-2402. doi:10.1063/1.1593798

[12] J. D. Wiggins-Camacho and K. J. Stevenson, "Effect of Nitrogen Concentration on Capacitance, Density of States, Electronic Conductivity, and Morphology of N-Doped Carbon Nanotube Electrodes," The Journal of Physical Chemistry C, Vol. 113, No. 44, 2009, pp. 19082-19090. doi:10.1021/jp907160v

[13] M. S. Saha, R. Li, X. Sun and S. Ye, "3-D Composite Electrodes for High Performance PEM Fuel Cells Composed of Pt Supported on Nitrogen-Doped Carbon Nanotubes Grown on Carbon Paper," Electrochemistry Communications, Vol. 11, No. 2, 2009, pp. 438-441. doi:10.1016/j.elecom.2008.12.013

[14] K. Gong, F. Du, Z. Xia, M. Durstock and L. Dai, "Nitrogen-Doped Carbon Nanotube Arrays with High Electrocatalytic Activity for Oxygen Reduction," Science, Vol. 323, No. 5915, 2009, pp. 760-764. doi:10.1126/science.1168049

[15] Y. Liu, Q. Fu and C. Pan, "Synthesis of Carbon Nanotubes on Pulse Plated Ni Nanocrystalline Substrate in Ethanol Flames," Carbon, Vol. 43, No. 11, 2005, pp. 2264-2271. doi:10.1016/j.carbon.2005.04.005

[16] Q. Bao, J. Zhang, C. Pan, J. Li, C. M. Li, J. Zang and D. Y. Tang, "Recoverable Photoluminescence of FlameSynthesized Multiwalled Carbon Nanotubes and Its Intensity Enhancement at $240 \mathrm{~K}$," The Journal of Physical Chemistry C, Vol. 111, No. 28, 2007, pp. 10347-10352. doi:10.1021/jp071460i

[17] G. Y. Zhang, X. C. Ma, D. Y. Zhong and E. G. Wang, 
"Polymerized Carbon Nitride Nanobells," Journal of Applied Physics, Vol. 91, No. 11, 2002, pp. 9324-9332. doi:10.1063/1.1476070

[18] N. Hellgren, J. Guo, Y. Luo, C. Såthe, A. Agui, S. Kashtanov, J. Nordgren, H. Ågren and J.-E. Sundgren, "Electronic Structure of Carbon Nitride Thin Films Studied by X-Ray Spectroscopy Techniques," Thin Solid Films, Vol. 471, No. 1-2, 2005, pp. 19-34. doi:10.1016/j.tsf.2004.03.027

[19] O. Björneholm, A. Nilsson, A. Sandell, B. Hernnäs and N. Mrtensson, "Determination of Time Scales for Chargetransfer Screening in Physisorbed Molecules," Physical Review Letters, Vol. 68, No. 12, 1992, p. 1892. doi:10.1103/PhysRevLett.68.1892

[20] S. Waidmann, M. Knupfer, J. Fink, B. Kleinsorge and J. Robertson, "Electronic Structure Studies of Undoped and Nitrogen-Doped Tetrahedral Amorphous Carbon Using High-Resolution Electron Energy-Loss Spectroscopy," Journal of Applied Physics, Vol. 89, No. 7, 2001, pp. 3783-3792.

doi:10.1063/1.1350999
[21] L. Liao, P. Fang and C. Pan, "Nitrogen-Doped Carbon Nanotubes from Amine Flames," Journal of Nanoscience and Nanotechnology, Vol. 11, No. 2, 2011, pp. 10601061. doi:10.1166/jnn.2011.3099

[22] P. Ayala, R. Arenal, M. Rümmeli, A. Rubio and T. Pichler, "The Doping of Carbon Nanotubes with Nitrogen and Their Potential Applications," Carbon, Vol. 48, No. 3, pp. 575-586. doi:10.1016/j.carbon.2009.10.009

[23] J. Zhao, H. Park, J. Han and J. P. Lu, "Electronic Properties of Carbon Nanotubes with Covalent Sidewall Functionalization," The Journal of Physical Chemistry B, Vol. 108, No. 14, 2004, pp. 4227-4230. doi:10.1021/jp036814u

[24] Y.-S. Min, E. J. Bae, U. J. Kim, E. H. Lee, N. Park, C. S. Hwang and W. Park, "Unusual Transport Characteristics of Nitrogen-Doped Single-Walled Carbon Nanotubes," Applied Physics Letters, Vol. 93, No. 4, 2008, p. 043113. doi:10.1063/1.2965805 